\title{
Using 'nudges' to encourage student engagement: an exploratory study from the UK and New Zealand
}

\author{
ALAN GRAHAM ${ }^{* 1}$, IAN TOON*2, KATE WYNN-WILLIAMS $* * 3$ and \\ NICOLA BEATSON**4
}

*University of Portsmouth, United Kingdom, ** University of Otago, New Zealand

1. Alan Graham ${ }^{1}$ : alan.graham@port.ac.uk

Portsmouth Business School

University of Portsmouth

Richmond Building

Portland Street

Portsmouth

PO1 3DE

United Kingdom

Tel: +442392844795

2. Ian Toon: ian.toon@port.ac.uk

Portsmouth Business School

University of Portsmouth

Richmond Building

Portland Street

Portsmouth

PO1 3DE

United Kingdom

Tel: +442392844720

3. Dr Kate Wynn-Williams: kate.wynn-williams@otago.ac.nz

Otago Business School

University of Otago

PO Box 56

Dunedin 9054

New Zealand

Tel: +64 34798429

4. Nicola Beatson: nicola.beatson@ otago.ac.nz

Otago Business School

University of Otago

PO Box 56

Dunedin 9054

New Zealand

Tel: +64 34798321

${ }^{1}$ Correspondence Author: Alan Graham, Portsmouth Business School, University of Portsmouth,

Richmond Building, Portland Street, Portsmouth PO1 3DE, United Kingdom. Email:alan.graham@port.ac.uk 


\title{
Using 'nudges' to encourage student engagement: an exploratory study from the UK and New Zealand
}

\begin{abstract}
This paper investigates whether student engagement is influenced by the use of specific nudges to direct behaviours to achieve a desired outcome. Evidence already exists that the use of nudges may have a positive effect in the wider population, although little prior research has demonstrated if there are potential benefits in the 'choice architecture,' or design, of such educational tools.

Using student cohorts studying core undergraduate accounting modules at United Kingdom and New Zealand universities, a number of measures of engagement, such as attendance and student opinions on the efficacy of certain nudges were investigated.
\end{abstract}

The results do not appear to show a significant improvement in student engagement, although a closer examination of the evidence suggests that this is likely to be a consequence of the type of nudge used and the way that an individual student relates to the message that the academic is trying to convey.

Despite no significant results, this paper is still able to provide a contribution to the important area of student engagement and nudge research. The lack of response may be interesting to others to build upon in this under-researched area.

KEY WORDS: Nudge, choice architecture, student engagement

\section{Introduction}

Strategies to improve accounting students' motivation and learning in Higher Education have been researched extensively with evident success (e.g. Harrell et al., 1985; Beattie et al., 1997; Lucas \& Mayer, 2005; Turner and Baskerville, 2013).

One aspect, which the authors believe warrants research into its potential transferability from the field of behavioural science to education, concerns the specific issue of whether particular 'nudges' and their practical implementation, for example the 'choice architecture' or particular design used by educators, may increase students' time on task and engagement on modules of study. This method of behavioural science is posited on the encouragement of individuals to change their existing ways of performing tasks by nudging them or giving specific information which results in an altering pattern of behaviour, rather than simply prescribing them to follow such paths. For example, by students being able to see for themselves the benefits of making a particular change to their way of learning, perhaps through peer pressure, they may decide to choose that option.

In the literature review that follows, examples of using nudges to successfully change human behaviour are considered, (e.g. Behavioural Insights 
Team, 2012) and possible links with higher educational practice are explored. The paper then researches whether the motivations behind of such behavioural change are sufficiently robust to be usable in student engagement initiatives.

In order to obtain an international educational perspective, data were obtained from surveying second year undergraduates studying an accounting module at a university in the UK and also first year undergraduates at a university in New Zealand. This then provided evidence to enable an analysis of whether or not 'choice architecture' could be used successfully to engage students in particular course modules. Using student feedback to various nudge interventions and also by analysing metrics measuring their attendance and participation at seminars, this research gauges how their perceived engagement may be affected by such initiatives.

The paper considers relevant literature in the area and then explains the details of the methodology used for conducting this research in the UK and in New Zealand. An analysis of the findings and the conclusions drawn therefrom follow.

\section{Literature Review}

Before addressing the matter of encouraging 'student engagement', it is important to define what is meant by the term. In one of the seminal pieces of research on student engagement in education, Astin (1984) defined it as being "the amount of physical and psychological energy that the student devotes to the academic experience" (p. 29). This notion has been built upon by Kuh (2009) and also Pascarella and Terenzini (2005), who have conceptualised engagement as the time and effort students invest in educational activities that are empirically linked to desired college outcomes. This encompasses various factors, including investment in the academic experience of college, interactions with faculty, involvement in co-curricular activities, and interaction with peers. Student interaction with the Virtual Learning Environment (VLE) has been shown to benefit their learning experience (De Lange et al., 2003; Gavira and Omoteso, 2013) and is also considered to be an important form of student engagement. It therefore seems irrefutable that a student simply being present in the classroom at any time does not, on its own, represent engagement, though it is evident that student attendance does provide for positive educational outcomes (Paisley and Paisley, 2004).

There are many examples in educational research of initiatives designed to use assessment as a means of trying to encourage student engagement and to alter behaviours to a desired state. For example, Johnstone et al. (2013) used a case study approach to 'nudge students to develop professional scepticism' (p. 991). In other examples, Meer and Chapman (2014) investigated the effects on student retention rates of using 'low stakes' assessment techniques with a view to promoting the behaviour of students towards actively utilising their feedback, while Grace and Gilsdorf (2004) focussed on enhancing students' oral communication skills by using an exercise that 'gently nudges students into the position of having to explain their technical mastery to others' (p. 168). 
While these findings suggest that it is possible to positively alter behaviours of students through careful course and module design, the emphasis on making subtle changes to student behaviours could be seen as a by-product of the main objective of improving student overall attainment and engagement. The approach in the following research is to investigate the direct effects of 'nudge theory' and 'choice architecture' in order to assess their effectiveness in student engagement.

Thaler and Sunstein (2008) defined a 'nudge' as:

any aspect of the choice architecture that alters people's behaviour in a predictable way without forbidding any options or significantly changing their economic incentives (p. 6).

The 'choice architecture' used is simply the careful design of the environments in which people make choices. A choice architect is therefore someone who has the ability to influence the way that people choose. An example of this is the positioning of food on shelves at supermarkets, where, for instance, the placing of chocolates beside champagne would be expected to lead to a more positive response and higher sales than if the same chocolates were positioned next to the meat counter.

When considering how this can be used in a teaching and learning context, it is necessary to consider the way that teachers make learning resources available to students and ask whether this can be done in a way that persuades students to take full advantage of them. This idea was shown to have had effective results by Healy and McCutcheon (2010), who used case studies to find that lecturers could guide or nudge students to a higher level of learning by careful encouragement in areas such as class discussion.

Bailes and Hoy (2014) took the idea of choice architecture a step further by developing principles of 'bounded free choice', where students and teachers are given the right to choose, while at the same time encouraging them to make 'good' choices. This involved, for example, encouraging students to self-regulate and set their own manageable deadlines (p. 492). Interestingly, they also found how the setting of simple positive defaults could be used instead of requiring individuals to make complex choices (p. 494). So, for instance, course leaders could create simple ways for students to automatically progress from one educational level of attainment to the next.

There are other opposing views on the effectiveness of nudge theory which are worthy of consideration. Goodwin (2012) argues that it is an ineffective strategy to promote behavioural change as it contravenes ideas of freedom and empowerment. It could therefore be seen in some way contrary to a student's freedom to decide their own best academic path. A study by Mols et al. (2015) goes even further and suggests:

nudge tactics offer limited scope for securing lasting behaviour change because, under this approach, new norms are not internalised as an integral part of the nudgee's self-concept and old habits can thus be expected to reappear once the choice architecture that produces particular outcomes is no longer present (p. 94). 
Mols et al. (2015) also propose the idea of some customers, once aware of the manipulation, becoming reactive to nudges and feeling the urge to 'defy the system'. It could be argued that this may be more prevalent in a young population of students, so this factor would need to be considered in any intervention. In addition, they argue that nudging involves attempts to influence behaviour by precluding reflection about the consideration of alternative courses of action (p. 84). This could be regarded as being counter to the purpose of educating students in Higher Education.

The ideas of student self-regulation previously mentioned have been shown to play an important part in education. Duckworth et al. (2011) showed how adolescent students were able to improve performance in tests through 'mental contrasting'. This involved imagining future desirable goals and comparing them with the more negative present reality, which then boosted commitment and achievement.

The findings of Bailes and Hoy (2014) also compared closely with those of Simpson (2010), who found that on a distance learning programme, tutors might be persuaded into making more personalised proactive contact by simply making it much easier to do so. Examples of such nudges might be making it easier for tutors to make proactive contact with students, for instance by the ability to send SMS texts from a website. This idea of 'ease of use' draws a comparison with work done by the UK Government Behavioural Insights Team which found that offering home owners a loft-clearance service can significantly increase the odds of installing loft insulation by over a factor of four, (Behavioural Insights Team, 2012). This result illustrates the importance of addressing non-monetary barriers to behaviour change, specifically in this case, the extra work and nuisance of clearing your loft.

Another area where nudge theory can be used is in the context of social norms and herd behaviours. These can also have a significant influence on choice (Ross and Nisbett, 1991; Cialdini, 2001), so that human beings rely heavily on those around them for cues on how to think, feel and act. This has been shown to take place in a number of fields, such as economics and finance where the decision rules that are chosen by optimising individuals will be characterised by group or herd behaviour, so that people will do what others are doing rather than using their own information, (Banerjee, 1992). Turning to an educational context, studies by Fassinger (1995) and McCabe et al. (2001) show that it is evident that peer pressure plays an important part in student behaviour, with the former study showing the effects on classroom interactions and the latter on how it can have an important effect on cheating. This form of peer pressure for the student age group extends beyond the classroom, for example in areas such as drug and alcohol consumption where the perceived norm can have a dominating effect on individuals' behaviours (Borsari and Carey, 2006; Rimal and Real, 2005). If such normative influences can be applied to positive student learning practices, then this could prove to have long term educational benefits.

Closely allied to the choice is the degree of commitment or consistency in those choices. For instance, it has been shown empirically that that a choice made actively - that is, one spoken out loud or written down or otherwise made explicit - is considerably more likely to direct someone's future conduct 
than the same choice left unspoken (Cialdini, 2001). This would explain why many academic institutions advocate some form of code of conduct or charter, both from an institution and student stand-point, where minimum expectations are expressly stated in the hope of adherence to those requirements.

It has also been shown that the act of providing regular reminders to individuals will encourage attendance. Calzolari and Nardotto (2011) showed that simple weekly reminders sent to gym users improved their attendance, although they warned of a problem of information overload if too many reminders competed for an individual's attention (p. 24). If this were to be applied to students, it could be problematic if it gave the impression of a nannying or an over-controlling burden on them, so any such measures would need to be applied sparingly and appropriately. This point is particularly important as the research is directed at university undergraduates who are at least 18 years of age and so are regarded as adults.

The literature reviewed shows that nudge theory, as widely used in other contexts, may be a useful tool in engaging students in their learning, though it is not without potential limitations, some of which have been explored above. The following section provides a methodology for testing its effectiveness in achieving better engagement in accounting students.

\section{Method}

A second year core accounting module at a UK university was chosen. This represented a wide range of student backgrounds, representing approximately 55\% home and European Union students. The population comprised $52 \%$ male and $48 \%$ female students.

A random group of 127 was selected, which represented half of the students from the entire cohort that was studying the module. The sample size and control group percentage was consistent with scientific models using a margin of error of 5\%, confidence level of $95 \%$, power of 0.8 and assumed odds ratio of 4 (Australian Biosecurity Cooperative Research Centre, 2014). The other 127 students therefore represented the control group. Once selected, a regular programme of fortnightly 'nudges' was sent to each of the students in the sample group (Appendix A). These were e-mailed to the students in the sample group at the start of weeks 3, 5, 7, 9 and 11 of the first term of the academic year and were designed to try to encourage student engagement by giving them information predominantly about positive student behaviour of the majority of the cohort who were taking this module. This approach followed the findings of Borsari and Carey (2006) and Rimal and Real (2005), referred to earlier, in which peer pressure was found to be a strong influence for the student age group.

Prior to the commencement of the research exercise, ethical approval had been gained from the UK University's ethics approval committee (covering also the New Zealand data collection through the same protocols), though the notion of informed consent could not realistically be sought from students in the sample group. This was because the idea of using nudges is to 
change behaviours without the subjects necessarily knowing that they are being encouraged to do so, in essence using a series of unconscious, almost 'subliminal' messages. It was therefore agreed that the nudges would be used in the first term of the academic year and, if it could be subsequently shown that these encouraged student engagement, then similar ones would be used thereafter to all students in the population, so ensuring that no student was disadvantaged by the intervention. It should be noted at this point that the ethical grounds for using nudges for behavioural change have been criticised by some (Goodwin, 2012; Mols et al., 2015; Hausman and Welch, 2010).

Using this approach, it was possible to measure the effects of the intervention on (1) seminar attendance, (2) seminar engagement, and lastly (3) engagement on Moodle, the online VLE. Each is discussed in further detail below:

(1) Seminar attendance is manually recorded at each weekly seminar by the tutor and then entered on a shared spreadsheet. As a further check to ensure reliability, the total number of students attending a class is counted by the tutor and reconciled to the total number of names recorded on the sheet.

(2) Seminar participation is measured by the tutor awarding an additional mark where the student has not only attended the seminar but has, in the opinion of the tutor, prepared sufficiently for the class by attempting the pre-seminar work that was set. These marks are entered on the same spreadsheet used to record attendance.

(3) Each student has access to, and is encouraged to use, a VLE site set up for the module by the module coordinator. As well as containing lecture notes and worked solutions to questions set, it also contains links to further resources, such as recommended articles related to the particular topics being taught that week. It is possible to monitor the volume and duration of individual student 'hits' to the VLE and the use of this can be seen as another indicator of student engagement (Liaw, 2008). For the purposes of this research paper, the measure used was whether or not the student had accessed the module's VLE site in the two week period leading up to the end of term.

In terms of reliability, the measure of seminar participation described above could potentially be circumvented by students who have been able to copy the work of other students attending earlier seminars to give the false impression of being adequately prepared for the seminar. While this is a limitation to this study, it is not considered to be a widespread problem by the authors and therefore it is not felt to be significant in the context of this research. Also, the act of accessing the VLE could be regarded as irrelevant if the student did not then use the opportunity to inquire into their studies further using the materials available. In addition there is the possibility that students could access materials using a friend's log in details, but again, for the purpose of this study, these factors were not regarded as materially significant.

In addition to the measures taken above, a sample of students was randomly chosen from the sample group following the conclusion of the nudge prompting exercise. In total, 15 students were each given a survey to complete 
to try to obtain more information behind their views of the nudges they had received (Appendix B).

The New Zealand classroom setting involved 252 students enrolled in first-year accounting, in the second semester of the academic year. Each semester has 13 teaching weeks, followed by a final exam period. The course had a financial accounting focus, including learning basic double-entry techniques and preparation of financial reports. Approximately half of the class had taken accounting as a high-school subject. The proportion of males to females was about equal and the age group was mainly 18-20 years, with some "mature" students (fewer than 10).

The survey was conducted during class time, and no attempt was made to record any personal information. As covered by the UK ethical clearance process protocol, there was total anonymity for the responses. Consequently, it was not possible, therefore, to determine with any accuracy whether the survey sample replicated the whole-class demographics.

Because there is no expectation that students in the accounting programme have any prior accounting knowledge, the introductory courses cover much of the material already studied by those students who took accounting during their high school years. Attendance is a chronic problem for first-year accounting courses, and this contributed significantly to the reduced number of survey responses as compared to the total class enrolment.

The questions used in the survey were designed to reflect the classroom situation at the New Zealand university. There is an expectation, but no compulsion, for students to attend class. The course has been taught for many years in its present format and to change the structure to mirror the UK setting would require significant bureaucratic processes. Therefore, there are some discrepancies between the settings which make direct comparisons difficult.

In an effort to increase attendance, there were a number of nudges used (see Appendix C):

- Weekly emails to the whole class were planned, but in light of student complaints about receiving too many emails from the University, only two class-wide emails were sent.

- A personal email was sent during the semester to students identified by tutors as having missed several tutorial sessions.

- $\quad$ One of the lecturers visited each of the eight tutorials twice during the semester, to enable a more informal discussion about upcoming assessments (mid-semester test and final exam), and also to allow for any questions or issues to be raised.

- $\quad$ 'Pop-up' messages were displayed during lectures at approximately the midpoint, with useful information about University policies, deadlines, suggestions for extra-curricular activities, information about 
professional accounting organisations, exchange opportunities for other universities and the internship programme.

Although the overall objective for both countries' studies was to assess whether or not nudges could act as a way of engaging students on accounting modules, there were differences of emphasis of approach. The common aim of the various methods and types of data collection was to provide rich and useful evidence from a variety of settings which could be analysed accordingly. The UK tests adopted an intervention using general e-mails to the sample group and gave clear measures with which to compare it with the control group, in order to see if it did result in a change in attendance patterns and VLE access. The follow up questions were aimed to further explore the rationale behind the behaviours resulting from the intervention. With the New Zealand tests, however, a different emphasis was made to focus more on possible types of nudges and also to explore in more detail some of the reasons given by students for attending class.

\section{Results}

\subsection{Second year UK undergraduate students}

The results were analysed using SPSS to determine whether there were any significant differences in the three measures between the sample group, which formed the intervention group, and the control group. Non-parametric statistical methods were used, as the measures were found not to be normally distributed across the groups and the histogram confirmed non-normal distribution of the data ${ }^{2}$.

Firstly, total attendance across the 12 weeks of the entire term was compared $^{3}$ and no significant difference was found between the sample and control groups $(\mathrm{p}>0.05)$.

Then, for each week of the sending of the nudge e-mail (i.e. five separate weeks in total), the first two indicators, seminar attendance and seminar participation, were used to compare the outcomes between the sample and control groups ${ }^{4}$. Finally, access to the module's VLE was used to enable the comparison of how many of each group had interacted with the VLE in the final two weeks of term.

The above tests were also repeated to establish whether there was any difference between the genders of the two groups.

The results are shown in Table 1 .

The results comparing the sample group with the control group showed that the interventions had no effect on attendance and participation, as measured in the week of each nudge. In addition, there was no evidence to

\footnotetext{
${ }^{2}$ Using K-S and Shapiro-Wilk normality tests ( $\left.\mathrm{p}=0.001\right)$.

${ }^{3}$ Using Mann Whitney non-parametric test.

${ }^{4}$ Using Chi-Squared non-parametric test
} 
suggest that it had increased student access of the VLE. These findings were confirmed for each gender, as well as for the group as a whole.

Table 1. Non-parametric tests between sample group and control group

\begin{tabular}{|c|c|c|c|}
\hline & $\begin{array}{l}\text { Significance (2- } \\
\text { tailed) }\end{array}$ & & Test \\
\hline $\begin{array}{l}\text { Attendance Week } 1 \text { to } \\
\text { Week } 12\end{array}$ & $\begin{array}{l}0.717 \\
\text { Sample Group } \\
(\mathrm{N}=127) . \text { Mean } \\
\text { rank = 126.91 } \\
\text { Control Group } \\
(\mathrm{N}=127) . \text { Mean } \\
\text { rank = 130.07 }\end{array}$ & & Mann-Whitney \\
\hline \multirow[t]{2}{*}{$\begin{array}{l}\text { Seminar attendance- } \\
\text { alternate weeks }\end{array}$} & & & Pearson Chi-Square \\
\hline & $\mathrm{All}^{5}$ & $\begin{array}{l}\text { Male ( } \mathrm{N}=66 \text { for } \\
\text { each group) }\end{array}$ & $\begin{array}{l}\text { Female ( } \mathrm{N}=61 \text { for } \\
\text { each group) }\end{array}$ \\
\hline Nudge 1 - Week 3 & 0.465 & 0.638 & 0.548 \\
\hline Nudge $2-$ Week 5 & 0.386 & 0.798 & 0.290 \\
\hline Nudge 3 - Week 7 & 0.784 & 0.802 & 0.358 \\
\hline Nudge 4 - Week 9 & 0.955 & 0.301 & 0.179 \\
\hline Nudge 5 - Week 11 & 0.706 & 0.875 & 0.431 \\
\hline \multicolumn{4}{|l|}{$\begin{array}{l}\text { Seminar participation- } \\
\text { alternate weeks }\end{array}$} \\
\hline Nudge 1 - Week 3 & 0.478 & 0.334 & 0.807 \\
\hline Nudge $2-$ Week 5 & 0.620 & 0.965 & 0.438 \\
\hline Nudge $3-$ Week 7 & 0.433 & 0.653 & 0.443 \\
\hline Nudge 4 - Week 9 & 0.404 & 0.533 & 0.133 \\
\hline Nudge 5 - Week 11 & 0.795 & 0.862 & 0.439 \\
\hline \multicolumn{4}{|l|}{ VLE access } \\
\hline Nudge $6-$ Week 12 & 0.865 & 0.572 & 0.311 \\
\hline
\end{tabular}

*All p>0.05, so no significant differences found between the sample group and the control group.

This suggests that students were not influenced by the nudges given. There are a number of possible reasons for this. Firstly, it may be that the receipt of e-mails on the subject merely added to the high volume of messages already going to their inboxes and that therefore the significance or importance of the message was somehow diluted - the information overload problem, referred to earlier (Calzolari and Nardotto, 2011). Another possible reason for the result is that the modern day student is more receptive to information emanating through social media applications such as WhatsApp, Facebook and Instagram as well as text messaging; this relates also to the ease of use factor

\footnotetext{
5 'All' represents males and females combined and compares the sample group data with corresponding data for the control group
} 
proposed by Simpson (2010), which leads to the inevitable conclusion that email may not be the most efficient way of communicating with students.

The survey responses showed some interesting findings. 5 of the 15 students (one-third) answered question 1 by stating that the receiving of regular e-mails about attendance and participation of students in the unit did not influence their decision to attend class. As the analysis of the quantitative data has shown, this did not seem to suggest any improvement in attendance, so either this confirmed their already held intention to attend, as was remarked by two of the students, or possibly the effect was actually negative, in other words a reaction against the positively intended nudges, as suggested by Calzolari and Nardotto (2011) and Mols et al. (2015). A similar minority of students (6 out of 15) also responded to question 2 that the receiving of regular e-mails did not encourage them to go on to the VLE and again the evidence of actual usage seemed to suggest that it indeed had little or no effect.

One student comment was particularly interesting. It was remarked that the nudges had no effect on attendance because 'they were not specific to me'. It may therefore be inferred from this that what is needed is personalised information and hints for it to be effective and that students and others are overburdened with a daily plethora of e-mails and information, much of which may seem to have no purpose to them and is therefore ignored.

\subsection{First year New Zealand undergraduate students}

In response to the question where students were asked to rank from 1 (most motivating) to 4 (least motivating) the use of: a) whole class e-mails, b) personal e-mails, c) visits to student tutorials by one of the lecturers, or d) popup messages appearing during lectures, the following results were obtained. From the 95 replies to this question, the most motivational of the four item in terms of attendance to class was d) - mean 2.24, closely followed by a) - mean 2.26. Less motivational to students were b) - mean 2.53 and c) - mean 2.64.

\section{See Table 2.}

Those nudges that were most motivational for students appeared to require the least degree of individual contact and commitment from them (class e-mail and pop-up messages). It therefore suggests that students would prefer not to have specific individual contact at all, whether that is by an individual e-mail or meeting with a staff member.

52 students also provided free-text responses when asked if there were any other motivators to encourage them to attend class. Half of these respondents (26) mentioned that it was the fact that they would be able to go through more examples and answers to questions which would not otherwise be available. A further 25\% (13) also stated the perceived link between attending and passing exams. Only 3 students referred to increasing 'engagement' with the lecturer and/or subject or the 'fun' of attending class. 
Table 2. Student motivations to attend class

\begin{tabular}{|c|c|c|}
\hline $\begin{array}{l}\text { 1. Student response to } \\
\text { question on potential } \\
\text { motivators }\end{array}$ & $\begin{array}{l}\text { Mean response }(\mathrm{N}=95) \\
1 \text { (most) to } 4 \text { (least) } \\
\text { motivating }\end{array}$ & \\
\hline -Pop-up message in lecture & 2.24 & \\
\hline -Whole class e-mail & 2.26 & \\
\hline -Personal e-mail & 2.53 & \\
\hline -Lecturer visit to tutorials & 2.64 & \\
\hline $\begin{array}{l}\text { 2. Other motivators to } \\
\text { attend class }\end{array}$ & $\begin{array}{l}\text { Number of responses } \\
(\mathrm{N}=52)\end{array}$ & $\%$ of total \\
\hline $\begin{array}{l}\text {-Go through } \\
\text { questions/examples }\end{array}$ & 26 & 50 \\
\hline -Help to pass exams & 13 & 25 \\
\hline -Help engagement/"fun" & 3 & 6 \\
\hline -Other & 10 & 19 \\
\hline $\begin{array}{l}\text { 3. Would your attendance } \\
\text { be affected by that of } \\
\text { other students? }\end{array}$ & $\begin{array}{l}\text { Number of responses } \\
(\mathrm{N}=87)\end{array}$ & $\%$ of total \\
\hline -Yes, definitely would & 39 & 45 \\
\hline -Probably would & 25 & 29 \\
\hline -Possibly would & 14 & 16 \\
\hline -No, definitely would not & 9 & 10 \\
\hline $\begin{array}{l}\text { 4. Reasons for answers to } \\
\text { 3. above }\end{array}$ & $\begin{array}{l}\text { Number of responses } \\
(\mathrm{N}=65)\end{array}$ & $\%$ of total \\
\hline -Fear of falling behind & 28 & 43 \\
\hline -Would attend anyway & 19 & 29 \\
\hline -Other & 18 & 28 \\
\hline
\end{tabular}

In question 3, students were asked if their class attendance pattern would be influenced if they knew that the vast majority of their fellow colleagues were attending.

These results show the powerful effect that the attendance of others has on students with $74 \%$ saying that it probably or definitely would make them more likely to attend class if they knew that the vast majority of other students were attending, a possible example of 'herd behaviour', as identified by Banerjee, 1992.

Of the 87 respondents to this question, 65 made additional comments giving reasons for their choice of answer. 
The largest response, the fear of falling behind others, appears to be consistent with the comments mentioned earlier, where the desire to go through answers to questions and to get help in passing exams formed the dominant set of replies.

Some interesting comments were also made under the ' $28 \%$ 'Other' category. These included:

- ' 'It is a human condition to follow the norm generally.'

- $\quad$ 'I am more influenced by my friends from my hall (and) place little value on the actions of strangers.'

- $\quad$ 'Because fellow students can encourage me to study hard.'

- 'If people are attending it shows the lecture is good.'

- $\quad$ 'Pack mentality.'

- 'It's easier to learn with friends.'

- ' Knowing that I have someone to talk to/learn with.'

These comments show how the effect of just being with friends and learning in a group environment can encourage attendance, although not to the same extent as the desire not to fall behind academically. It does however show that the end result of higher eventual grades is not necessarily at the forefront of the minds of all students. Johnson et al., 2007 refer to the existence in Higher Education of 'cooperative learning' in the context of social interdependency theory, which has been shown to result in more effective learning.

Students were asked their opinions on the level of importance of different types of class activity. In particular, the distinction given to the importance of the achievement of high grades compared with that of actual learning and the acquisition of new knowledge was recorded.

The results are shown in Table 3.

As could be expected, the fact that the final exam accounted for by far the largest proportion of the overall assessment meant that students regarded this to be the most important activity, both from a grade attainment and a learning point of view (means of 9.81 and 9.44 respectively). It is noticeable however from these results that the assessment weighting appears to play little part in responses for the importance of learning given for the first three activities, despite the weighting varying from $5 \%$ to $20 \%$. In addition, the Pearson product moment correlation coefficients between the responses for each of the activities range from $r=0.224$ to $r=0.441$, which indicate that there is an absence of a strong correlation between the responses for the importance of grade and of learning. 
Table 3. Student responses to activity by grade importance and learning importance

\begin{tabular}{|l|l|l|l|l|}
\hline Activity & $\begin{array}{l}\text { Weighting } \\
\%\end{array}$ & $\begin{array}{l}\text { Importance } \\
\text { of grade (1, } \\
\text { no } \\
\text { importance to } \\
\text { 10, high } \\
\text { importance). } \\
\text { Mean }\end{array}$ & $\begin{array}{l}\text { Importance } \\
\text { of learning } \\
(1, \text { no } \\
\text { importance to } \\
10, \text { high } \\
\text { importance). } \\
\text { Mean }\end{array}$ & $\begin{array}{l}\text { Pearson } \\
\text { product } \\
\text { moment } \\
\text { correlation } \\
\text { coefficient, } r\end{array}$ \\
\hline $\begin{array}{l}\text { Weekly } \\
\text { tutorial } \\
\text { assignments }\end{array}$ & 5 & 6.05 & 7.41 & 0.361 (med) \\
\hline $\begin{array}{l}\text { Weekly } \\
\text { tutorial } \\
\text { quizzes }\end{array}$ & 5 & 5.95 & 6.89 & 0.358 (med) \\
\hline $\begin{array}{l}\text { Summative } \\
\text { practice test }\end{array}$ & 20 & 8.55 & 6.63 & 0.384 (med) \\
\hline $\begin{array}{l}\text { Mid } \\
\text { semester } \\
\text { test }\end{array}$ & 20 & 8.97 & 8.86 & 0.441 (med) \\
\hline Final exam & 50 & 9.81 & 9.44 & $\begin{array}{l}0.224 \\
\text { (small) }\end{array}$ \\
\hline N=95 & & &
\end{tabular}

\subsection{Comparisons between the two countries}

The results from the UK indicate that the use of generic e-mail nudges to students had little effect on engagement as evidenced by attendance in seminars and access to the module VLE. These findings, together with the additional comment from the survey that the nudges had no influence "because they were not specific to me" would suggest that a more personalised approach from lecturers would have been preferable. Yet this contrasts with the overall findings from the New Zealand group in Table 2, where the two most personalised nudges of the four considered, namely the use of personal emails and the lecturer visit to tutorials, were regarded as having the lowest motivational effects on students. In contrast, general e-mails and pop-up messages in lectures were regarded as having the highest motivational effects.

Another interesting contrast was evident from the New Zealand students' apparent strategic reasons for attendance, namely the fear of falling behind fellow students and the consequent recognition that others' attendance is a strong influencing factor. In the UK group, three of the five fortnightly nudges given (See Appendix A - numbers 1, 4, and 5) specifically referred to other students' attendance and accessing of the VLE, yet, as has been shown, these had no impact on the intervention group's actions.

One area of similarity, however, between the two cohorts was in the relatively low number of responses for the notion that attendance in itself was 
linked to a positive engagement in the subject, where the New Zealand survey findings mirrored those from the UK cohort.

\subsection{Implications for practice}

The differences found between the two countries have many potential implications if this is to be used to encourage student engagement in the future. For example, the relative buoyancy of graduate job markets between various countries could affect a student's perception of the importance of achieving a particular grade. It may therefore be that the nudge approach has more success when the desire to reach such a goal conveys perceptible advantages to the student. Another factor which would need consideration would be the effectiveness of the approach on students at different year levels. If, as suggested in the data from the New Zealand first year cohort, students felt particular inherent anxieties and a 'fear of falling behind' then the use of such techniques might be more beneficially applied to newer students, rather than those who felt more settled and confident by virtue of the fact that they had experienced Higher Education for longer.

\subsection{Implications for theory}

From a theoretical standpoint, it may be inferred that the multi-faceted pressures that different students face to succeed academically could be used to explore further evidence to inform the most effective pedagogies. Another possible implication concerns the importance of the methods and types of mechanism used to communicate with learners. If teachers have a better theoretical understanding of these, then it may be possible to target important information more effectively.

\subsection{Limitations of study}

The study was restricted to two groups of undergraduate students, one at a UK university and the other at one in New Zealand. A wider study, including students from other countries would have enabled more detailed comparisons to be made. Another potential limitation is the view that the more prompts or nudges someone receives, the less their effectiveness in changing behaviour as 'information overload' sets in (Calzolari and Nardotto, 2011). This effect would be difficult to measure. Finally, the study considered a limited number of nudges, but there are many other possible methods which could have been used and assessed and which could be the subject of future research.

\section{Conclusion}

In this preliminary study, the results from the UK indicated that while there was no conclusive evidence that nudges had a noticeable effect on student engagement generally, there is plenty of scope to investigate this idea further, particularly as it is a relatively unexplored area of research. It seems that if nudges are to make students more engaged in their learning, then it is important to consider how the message is communicated to students and to be 
more imaginative than simply assume that the sending of reminder e-mails is the best means. In terms of conveying information, the use of 'pop-up' messages in the New Zealand cohort was better received than the other nudges offered to them, so reinforcing the challenge for educators to think carefully not just about the message they are trying to send to students, but also the mode of communication, if we are to encourage engagement.

The data from New Zealand also showed that one of the key reasons why students attend classes is a feeling that there is going to be some measurable improvement in their chances of doing well in subsequent assessments. Previous research, such as Paisley and Paisley (2004), has shown that the more classes a student attends, the better will be his/her final examination performance. In this respect, students can be seen to have a strategic view of how best to achieve their target and of making sure that they are not left behind others in their cohort. Therefore any nudges which remind them that attendance is linked to success will have some merit, while attending for any perceived gain in the learning experience appears to be of a secondary concern to most students.

It is concluded that the use of carefully designed nudges, which students are consequently eager to receive and respond to, may help in their engagement and hence in their learning experience. It has also been found that the choice architecture, as defined earlier, plays an important part in this process, since the ease with which students can access relevant information can have a positive effect on their engagement.

\section{Suggestions for future research}

The apparent lack of a conclusive outcome to this research should not preclude useful future research from being conducted in the area of education. Indeed, the fact that the use of nudges has had success in changing human behaviours in other fields (Behavioural Insights Team, 2012; Borsari and Carey, 2006; Rimal and Real, 2005) would tend to support this argument.

Further research in this area should address the issue of which specific nudges could have the greatest influence on engagement. This is particularly pertinent as new methods of communication and uses of different technologies are playing an increasing role in education generally. A measurement of the relative effects of contacting students using conventional emails, texts, phone calls, and messaging via WhatsApp, Twitter and Facebook, for example, may be considered. This could be refined further by considering the timing and duration of such interfaces.

Other potentially useful considerations for research would be to explore in more detail the factors behind successful student engagement, for which it would be necessary to explore learners' expectations and determine whether or not they were being adequately addressed. Finally, the possible effects of the student's ethnic or cultural background on the responsiveness to different types of nudge might have resulted in the different recorded outcomes from the UK and New Zealand cohorts. This could be investigated 
as part of a future study involving multicultural student groups from various countries.

This research did not receive any specific grant from funding agencies in the public, commercial, or not-for-profit sectors. 


\section{References}

Astin A. (1984) Student involvement: a developmental theory for higher education. Journal of College Student Personnel 25, 297-308.

Australian Biosecurity Cooperative Research Centre (2014). Retrieved from http://epitools.ausvet.com.au/content.php?page $=$ casecontrolSS \&P $1=0.05 \& R R=4 \&$ Conf $=0.95 \&$ Power $=0.8$

Bailes, L. P. and Hoy, W. K. (2014). Designing school contexts for success: paternalism or libertarianism? International Journal of Educational Management, 28(5), 484-497.

Banerjee, A. (1992). A simple model of herd behavior. The Quarterly Journal of Economics, 107(3), 797-817.

Beattie, V., Collins, B. and McInnes, B. (1997). Deep and surface learning: a simple or simplistic dichotomy? Accounting Education: An International Journal, 6(1), 1-12.

Behavioural Insights Team (2012). Annual Update 2011-12. Retrieved from https://www.gov.uk/government/uploads/system/uploads/attachment_data/file/83719/ Behavioural-Insights-Team-Annual-Update-2011-12_0.pdf

Borsari, B. and Carey, K. (2006). How the quality of peer relationships influences college alcohol use. Drug and Alcohol Review, 25(4), 361-370.

Calzolari, G. and Nardotto, M. (2011). Nudging with information: a randomized field experiment on reminders and feedback, Centre for Economic Policy Research.

Cialdini, R. (2001). Harnessing the Science of Persuasion. Reprint R0109D. Harvard Business Review.

de Lange, P., Suwardy, T. and Mavondo, F. (2003). Integrating a virtual learning environment into an introductory accounting course: determinants of student motivation, Accounting Education, 12(1), 1-14.

Duckworth, A. L., Grant, H., Loew, B., Oettingen, G., \& Gollwitzer, P. M. (2011). Self- regulation strategies improve self-discipline in adolescents: Benefits of mental contrasting and implementation intentions. Educational Psychology, 31, 17-26.

Fassinger, P. (1995). Understanding Classroom Interaction: Students' and Professors' Contributions to Students' Silence. The Journal of Higher Education, 66(1), 82-96.

Gavira, R. and Omoteso, K. (2013). Perceptions of the Usefulness of Virtual Learning Environments in Accounting Education: A Comparative Evaluation of Undergraduate Accounting Students in Spain and England, Accounting Education: An International Journal, 22(5), 445-466.

Goodwin, T. (2012). Why we should reject 'nudge'. Politics, 32(2), 85-92.

Grace, D. and Gilsdorf, J. (2004). Classroom strategies for improving students' oral communication skills, Journal of Accounting Education, 22, 165-172.

Harrell, A., Caldwell, C. and Doty, E. (1985). Within-Person Expectancy Theory Predictions of Accounting Students' Motivation to Achieve Academic Success, The Accounting Review, 60(4), 724-735.

Hausman, D. M., \& Welch, B. (2010). Debate: To Nudge or Not to Nudge, .Journal of Political Philosophy, 18(1), 123-136. 
Healy, M. \& McCutcheon, M. (2010). Teaching with Case Studies: An Empirical Investigation of Accounting Lecturers' Experiences, Accounting Education: An International Journal, 19(6), 555-567.

Johnson, D. W., Johnson, R. T., \& Smith, K. (2007). The state of cooperative learning in postsecondary and professional settings. Educational Psychology Review, 19(1), $15-29$.

Johnstone, N., Mackintosh, B. and Phillips, F. (2013). Second Round Electronics: A Case for Critical Thinking, Issues in Accounting Education, 28(4), 983-1007.

Kuh G. (2009). What student affairs professionals need to know about student engagement. Journal of College Student Development 50, 683-706.

Liaw, S.S. (2008). Investigating perceived students' satisfaction, behavioural intention, and effectiveness of e-learning: A case study of the Blackboard system. Computers \& Education, 51(2), 864-873.

Lucas, U. and Mayer, J. (2005). 'Towards a mapping of the student world: the identification of variation in students' conceptions of, and motivations to learn, introductory accounting. The British Accounting Review, 37(2), 117-204.

McCabe, D., Trevino, L. and Butterfield,K.(2001). Cheating in Academic Institutions: A Decade of Research, Ethics \& Behavior, 11(3), 219-232.

Meer, N. and Chapman, A. (2014). Assessment for confidence: Exploring the impact that low-stakes assessment design has on student retention. The International Journal of Management Education, 12, 186-192.

Mols, F., Haslam, S. A., Jetten, J., \& Steffens, N. K. (2015). Why a nudge is not enough: A social identity critique of governance by stealth. European Journal of Political Research, 54(1), 81-98.

Paisley, C. and Paisley, N., (2004). Student attendance in an accounting module reasons for non-attendance and the effect on academic performance at a Scottish University, Accounting Education: An International Journal, 13(1), 39-53.

Pascarella E.T. \& Terenzini P.T. (2005) How College Affects Students: A Third Decade of Research. Jossey-Bass, San Francisco, CA.

Rimal, R. and Real, K. (2005). How Behaviors are Influenced by Perceived Norms: A Test of the Theory of Normative Social Behavior. Communication Research, 32(3), 389-414.

Ross, L. and Nisbett, R. (1991). The person and the situation: Perspectives of social psychology. McGraw-Hill: New York.

Simpson, O. (2010),. The CWP Retention Literature, Final Report, The Open University. Retrieved from http://www.ormondsimpson.com/USERIMAGES/Retention\%20literature\%20review. pdf

Thaler R. and Sunstein C., (2008). Nudge: Improving Decisions About Health, Wealth, and Happiness. Yale University Press: New Haven.

Turner, M. and Baskerville, R. (2013). The Experience of Deep Learning by Accounting Students. Accounting Education: An International Journal, 22(6), 582604. 


\section{Appendix A. Fortnightly nudges e-mailed to 2nd year UK sample group}

1. Attendance for the last week in the unit was $79 \%$. If you did not attend, you may well have missed out on something important.

2. Last week, $72 \%$ of students came to seminars having also attempted the homework questions. Practising questions is the key to ultimate exam success.

3. Please note that Moodle contains important unit information, including links to reading lists, professional bodies and other resources. Don't miss out!

4. In the last two weeks, $77 \%$ of students taking the Financial Reporting unit have accessed the Moodle site for information.

5. In 2011, the overall attendance and participation mark for the unit was 59\% and the unit pass rate was $75 \%$. The following year, the attendance and participation mark rose by 10 percentage points and so did the pass rate!

\section{Appendix B. Follow up survey questions to members of the UK sample group}

1. Did the receiving of regular e-mails about attendance and participation of students in the unit influence your decision to attend class? Yes/No

-1a) If you answered No, then why not?

$-1 b)$ If you answered Yes to the above, to what extent (answer on a scale of 1-5 with 1 being very little and 5 being a great amount) do you believe that it encouraged you to attend?

2. Did the receiving of regular e-mails encouraging you to go on to Moodle influence your decision to use the site more? Yes/No

-2a) If you answered No, then why not?

-2b) If you answered yes to the above, to what extent (answer on a scale of 1-5 with 1 being very little and 5 being a great amount) do you believe that it encouraged you to attend?

3. Do you have any other comments you wish to make on how we can help encourage more attendance and participation in classes on the course? Please write your comments below.

\section{Appendix C. Email nudges sent to 1st year New Zealand sample group}

\section{Email sent in week 2 - to whole class:}

1. The lecture exercise that we worked through in class today (Thursday) is now posted on Blackboard, in the week's Lecture Notes. Remember to read through Chapter 2 for a good discussion of this week's topics.

Next week (week 3) we will be covering Balance Day Adjustments and how to prepare an Adjusted Trial Balance. Chapter 3 in the textbook is essential reading for this!

\section{Email sent in week 7 - to whole class:}

2. It has come to my attention that many of you are not coming to your weekly tutorial session for ACCT 102. Possibly you are attending sessions at different times than your official stream. If you aren't attending regularly, I would like to encourage 
you to start! The tutorials are designed for you to be able to talk and discuss things in smaller groups. They are also the way to check your work and see the suggested solutions to the weekly homework exercises. If there are problems or difficulties that we can help with, please let me know.

\section{Email sent in week 9 - to students marked as having been absent for more than three weeks:}

3. I am writing to follow up some concerns from your tutor that you seem to be missing many of your scheduled tutorial sessions. There may be good reasons for this, and of course it is your decision whether to attend or not. I would just like to take this last opportunity, while there are still a number of weeks left in the semester, to encourage you to attempt the weekly exercises and quizzes. Not only are you missing out on the chance to improve your internal marks, attempting the exercises gives you good practice for the final exam.

I am happy for you to contact me if there are any problems that I can help with.

\section{Appendix D. Survey of 1st year New Zealand sample group}

We have tried to find new ways to encourage your interest and participation this semester, and we would like to find out whether you have found them useful.

Completing this survey is completely voluntary, and it is anonymous. You don't have to provide any personal information at all. Any comments you care to provide will be very helpful, and we appreciate your suggestions.

1. Please rank the following activities in order of value to you.

Use 1 to indicate the activity that made you feel the most motivated, down to 4 for the least useful.

\begin{tabular}{|l|l|}
\hline & weekly emails to the whole class \\
\hline & personal emails if you missed a tutorial session \\
\hline & visits to the tutorials by one of the lecturers \\
\hline & pop-up messages during lectures \\
\hline
\end{tabular}

What else makes you want to attend class and participate in class activities? (Please write a few words in the space below)

2. We are interested to know how much importance you place on grades as compared to the actual learning and new knowledge that happens with different activities. Please indicate the level of importance you put on learning and grades for each activity listed below.

Using a scale of $1-10$, use $\mathbf{1 0}$ to indicate the highest level of importance you can imagine, and $\mathbf{1}$ to mean this activity has no importance for you at all. 


\begin{tabular}{|l|c|c|c|}
\hline \multicolumn{1}{|c|}{ class activity } & $\begin{array}{c}\text { \% of course } \\
\text { grade }\end{array}$ & $\begin{array}{c}\text { importance } \\
\text { of grades }\end{array}$ & $\begin{array}{c}\text { importance } \\
\text { of learning }\end{array}$ \\
\hline weekly tutorial assignments & $5 \%$ & & \\
\hline weekly tutorial quizzes & $5 \%$ & & \\
\hline MYOB project & $20 \%$ & & \\
\hline mid-semester test & $20 \%$ & & \\
\hline final exam & $50 \%$ & & \\
\hline
\end{tabular}

What would make a difference to the value you place on these activities? (Please write a few words in the space below)

Is there a point below which you don't think an assessment is worth bothering with?

If so, please indicate where that point is.

$0 \%$ $100 \%$

3. If you knew that the vast majority of your fellow students on your course were regularly attending classes, to what extent would this make you more likely to attend classes also?

Please circle below 1 to 4 .

\begin{tabular}{|c|c|c|c|}
\hline $\begin{array}{l}\text { Yes, it would } \\
\text { definitely make } \\
\text { me more likely to } \\
\text { attend classes }\end{array}$ & $\begin{array}{l}\text { It probably would } \\
\text { make me more } \\
\text { likely to attend } \\
\text { classes }\end{array}$ & $\begin{array}{l}\text { It possibly would } \\
\text { make me more } \\
\text { likely to attend } \\
\text { classes }\end{array}$ & $\begin{array}{l}\text { No, it would } \\
\text { definitely not } \\
\text { make me more } \\
\text { likely to attend } \\
\text { classes }\end{array}$ \\
\hline 1 & 2 & 3 & 4 \\
\hline
\end{tabular}

Please write a few words below explaining your choice

Thank you for taking part in this survey. 